\title{
Death-associated protein kinase: A molecule with functional antagonistic duality and a potential role in inflammatory bowel disease (Review)
}

\author{
SARA STEINMANN ${ }^{1 *}$, KRISTINA SCHEIBE $^{3 *}$, KATHARINA ERLENBACH-WUENSCH $^{2}$, \\ CLEMENS NEUFERT $^{3 * *}$ and REGINE SCHNEIDER-STOCK ${ }^{1 * *}$ \\ ${ }^{1}$ Experimental Tumorpathology, ${ }^{2}$ Institute of Pathology, FAU Erlangen-Nürnberg, 91054 Erlangen; \\ ${ }^{3}$ Department of Medicine 1, University Hospital Erlangen, FAU Erlangen-Nürnberg, \\ Kussmaul Campus for Medical Research, 91052 Erlangen, Germany
}

Received December 29, 2014; Accepted March 6, 2015

DOI: $10.3892 /$ ijo.2015.2998

\begin{abstract}
The cytoskeleton-associated serine/threonine kinase death-associated protein kinase (DAPK) has been described as a cancer gene chameleon with functional antagonistic duality in a cell type and context specific manner. The broad range of interaction partners and substrates link DAPK to inflammatory processes especially in the gut. Herein we summarize our knowledge on the role of DAPK in different cell types that play a role under inflammatory conditions in the gut. Besides some promising experimental data suggesting DAPK as an interesting drug target in inflammatory bowel disease there are many open questions regarding direct evidence for a role of DAPK in intestinal inflammation.
\end{abstract}

\section{Contents}

1. Introduction

2. DAPK - structure and functional domains

3. Regulation of DAPK

4. DAPK interactome and substrates

5. Molecular Biology of IBD

6. Link of IBD and cancer

7. DAPK regulation and function in different cell types of the intestine

8. Open questions and future challenges

Correspondence to: Professor Regine Schneider-Stock, Experimental Tumorpathology, Institute of Pathology, FAU Erlangen-Nürnberg, Universitätsstr. 22, 91054 Erlangen, Germany

E-mail: regine.schneider-stock@uk-erlangen.de

"Contributed equally; * Joint senior authorship

Key words: inflammatory bowel disease, death-associated protein kinase, colorectal carcinogenesis

\section{Introduction}

Phosphorylation of proteins by kinases is the most frequent protein modification and plays a key role in multiple signal transduction pathways in normal and cancer cells. In recent years protein kinases have become novel promising candidates for targeted anticancer therapy. To identify and characterize kinases as biomarkers for tumor transformation or progression is a major challenge for clinicians, oncologists, and molecular biologists. The cytoskeleton-associated serine/ threonine kinase death-associated protein kinase (DAPK) has been described as a cancer gene chameleon showing functional antagonistic duality in a cell type and context specific manner (1). Cancer genes are classified according to whether they function in a dominant or recessive manner. Dominant cancer genes (oncogenes) are constitutively activated by gain of function mutations and stimulate cell growth and survival. For recessive genes (tumor suppressors) the loss of function leads to the inactivation and loss of cell cycle control and repair capacity. Mutations in the DAPK gene are very rare. There are many other mechanisms such as promoter hypermethylation, autophosphorylation of calmodulin-domain, protein degradation or inhibitory phosphorylations of the DAPK molecule itself that might inactivate DAPK. Noteworthy, DAPK can act not only through its catalytic activity but also triggers multiprotein complexes through its scaffold function (2). The broad regulation levels of this kinase let it be involved in many different cellular functions such as cell death (apoptosis, anoikis, autophagy), repair and mechanosensing (3-5).

Colorectal cancer (CRC) develops in a multistep process and specific molecular hits have been defined that are closely correlated with single morphological alterations along the carcinogenesis process summarized in the Vogelstein model (6). For sporadic cancer two major different pathogenetic pathways exist: the chromosomal instability phenotype (CIN, counts for $85 \%$ of tumors) and the microsatellite instability phenotype (MSI, counts for $15 \%$ of tumors), both are caused by loss of a general genetic stability. In 2012 a three-group classification system has been reported according to alterations in known signal transduction pathways: i) WNT and TGF $\beta$ signaling 
ii) PIK3CA and RAS signaling, and iii) p53 signaling $(7,8)$. Also epigenetic alterations contribute to altered gene expression in colorectal cancer (9). In this regard a $\mathrm{CpG}$ island methylator phenotype has been described (CIMP). Moreover, CIMP is included in different molecular classification systems. Nevertheless its prognostic predictive role is not clarified due to lack of unified test systems. There are also other risk factors for the development of a colorectal carcinoma. Patients with inflammatory bowel disease (IBD) show an increased risk for tumor development. The pathogenesis of IBD-associated carcinogenesis is poorly understood. What we know is that similar to sporadic cancer also IBD-associated cancer is a consequence of a sequence of single molecular alterations (10).

Although it is not surprising that many molecular hits are overlapping in both cancers the major difference is the frequency and the timing of these molecular alterations $(10,11)$. For DAPK in sporadic colorectal cancer there is a loss of protein by promoter hypermethylation already in very small tumors and thus DAPK loss plays a role at very early steps of the tumor formation process (12). Moreover, loss of DAPK in colorectal carcinomas has been associated with higher lymph node metastasis and poor prognosis (13). In contrast, besides an early inactivation by promoter methylation in a subset of tumors, DAPK is remarkably activated in colon cancer in the setting of inflammation (14). So far only one of the two major IBD forms has been studied for DAPK expression: ulcerative colitis (UC) (15). There are no data on the role of DAPK in Crohn's disease (CD). Recently, it has been shown that DAPK may play a role in UC-associated tumor transformation (16). Pro- as well as anti-inflammatory functions have been suggested for DAPK, dependent on the cell type and stimulus.

As the development of colorectal cancer is a long-term complication of chronic inflammation it would be helpful for patient management to identify molecular biomarkers that predict the risk of tumor development as early as possible. DAPK might be a possible candidate for therapeutic intervention but its gene chameleon nature needs an ultimate understanding of its functions and regulation in different cell types under different inflammatory stimuli.

\section{DAPK structure and functional domains}

DAPK1 (here referred as DAPK) represents one of the five members of the DAPK family (4). These molecules differ in size and subcellular localization (Fig. 1, Tables I-III). DAPKrelated protein 1 (DRP-1, DAPK2) and zipper-interacting protein kinase (ZIPK, DAPK3) share the highest homology with approximately $80 \%$ at the $\mathrm{N}$-terminus whereas DAPK related apoptosis inducing kinase 1 and 2 (DRAK1, DRAK2) have only $50 \%$ homology compared with DAPK (17-20). In contrast to the cytoskeleton-associated family members, ZIPK has also nuclear functions and interacts with transcription factors such as ATF4 and STAT3 (21). DAPK is a multidomain structure protein that exerts its action through the catalytic activity and phosphorylation of specific substrates with DAPK-containing motifs or as a scaffold protein by stabilizing or triggering multiprotein complexes. One of the most important functional domains is the calmodulin autoregulatory domain that is localized inside of the catalytic cleft. Calmodulin binding leads to changes in conformation which
Table I. Interacting partners of DAPK.

\begin{tabular}{|c|c|c|}
\hline Protein & OMIM ID & $\begin{array}{l}\text { Binding domain } \\
\text { on DAPK }\end{array}$ \\
\hline $14-3-3$ & 609009 & Not defined \\
\hline Actin & 102560 & $\begin{array}{l}\text { Cytoskeletal- } \\
\text { binding region }\end{array}$ \\
\hline Beclin-1 & 604378 & Not defined \\
\hline $\begin{array}{l}\text { Calmodulin } \\
(\mathrm{CaM})\end{array}$ & 114180 & $\begin{array}{l}\text { Calmodulin } \\
\text { regulatory domain }\end{array}$ \\
\hline Cathepsin B & 116810 & C-terminal region \\
\hline DIP1 (MIB1) & 608677 & Ankyrin repeats \\
\hline ERK1/2 & $601795 / 176948$ & Death domain \\
\hline Hsp90 & 140571 & Kinase domain \\
\hline KLHL20 & Q9Y2M5 (UniProt) & Death domain \\
\hline LAR (PTPRF) & 179590 & Ankyrin repeats \\
\hline LIMK/cofilin & $601329 / 601442$ & Not defined \\
\hline MAP1B & 157129 & Kinase domain \\
\hline p38 MAPK & 600289 & Not defined \\
\hline p53 & 191170 & Not defined \\
\hline PP2A & 176915 & ROC-COR domain \\
\hline PKD & 173900 & Not defined \\
\hline RSK & 601684 & Not defined \\
\hline Scr & 190090 & Ankyrin repeats \\
\hline STAT3 & 102582 & Not defined \\
\hline TNFR-1 & 191190 & Not defined \\
\hline $\mathrm{TSC} 2$ & 191092 & Death domain \\
\hline UNC5H2 & 607870 & Death domain \\
\hline ZIPK (DAPK3) & 603289 & Kinase domain \\
\hline
\end{tabular}

Bold, inflammation-associated interaction partners of DAPK.

allow DAPK activation via binding to its substrates (22). Also auto-phosphorylation at residue Ser308 inhibits the DAPK function by reducing its affinity to calmodulin (23).

Besides the prominent function of the catalytic subunit all additional domains such as the ankyrin repeats, the ROC-COR domain in the cytoskeleton-binding region, and the death domain have particular function in the concerted action of this multifunctional protein (Tables I and II). DAPK contains 8 ankyrin repeats that determine primarily the localization of DAPK. Moreover, this region is important for protein-protein interactions. Thereby a negative DAPK regulator, the DAPKinteracting protein (DIP1), is binding at the ankyrin repeat domain. Phosphorylation of Tyr491/Tyr492 by Src tyrosine kinase within the ankyrin repeat domain leads to inactivation of DAPK (24) whereas the interaction with the phosphatase LAR reconstitutes the activity of DAPK (24).

Bialik and Kimchi et al (25) have shown that DAPK is a member of the ROCO protein family that is characterized by the tandem appearance of the ROC (Ras-like GTPase) domain, and a characteristic COR (C-terminal of Roc) domain. The ROC domain overlaps with the cytoskeleton binding region of DAPK and mediates the GTP binding at the P-loop motif. This 

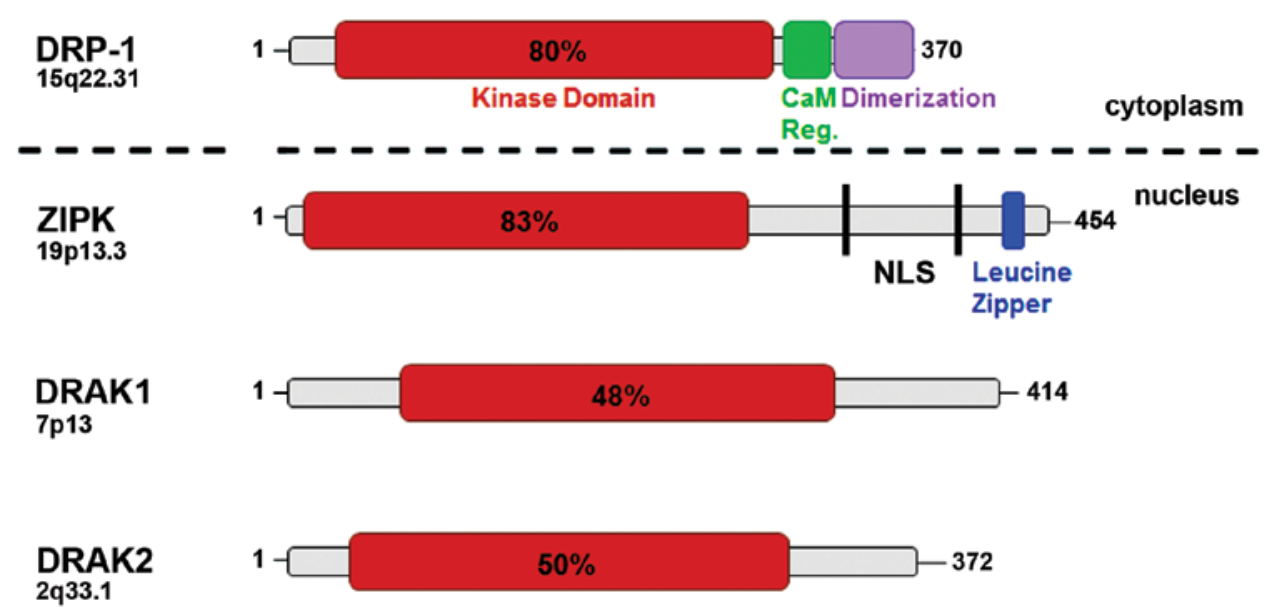

Figure 1. Structure of different isoforms and functional domains of DAPK family members. Percentage gives structural similarity to the DAPK molecule.

led to the definition of DAPK as a GTP-binding protein with intrinsic GTPase activity whereby GTP binding negatively regulates DAPK's activity. The serine/threonine protein phosphatase PP2A, the only known phosphatase dephosphorylating the inactive pDAPK ${ }^{\mathrm{Ser} 308}$, also interacts with the ROC-COR domain of DAPK (26).

The death domain at the DAPK C-terminus mediates DAPK's function in Fas- and TNF-induced cell death (3). It interacts with microtubule affinity regulating kinases (MAPK1/2) that phosphorylate tau and thereby destabilize microtubules (27). ERK is known to phosphorylate DAPK at Ser735 in the death domain increasing its catalytic activity. The death domain-mediated phosphorylation of the TSC2 protein leads to autophagy induction (28). Also the interaction of the transmembrane receptor $\mathrm{UNC} 5 \mathrm{H}$ is mediated through the death domain. UNC5H recruits DAPK and PP2A to the lipid rafts where Ser308 is then dephosphorylated leading finally to an increase in activity. There are death domain-mediated interactions that result in a destabilization of DAPK such as the binding with KLHL20, an adaptor for the Cullin3 ligase, which promotes the proteasomal degradation of DAPK.

\section{Regulation of DAPK}

The cellular level of DAPK can be regulated manifold. On the transcriptional level promoter hypermethylation has been described that strongly correlates with DAPK protein loss $(21,29,30)$. The promoter of DAPK has a high density of $\mathrm{CpG}$ islands and motifs for a number of transcription factors are located within these regions such as for NFKB, E2F1 or AP1 (21). For colon tumors, the literature reports a wide range of 5-80\% methylation frequency possibly caused by investigating different $\mathrm{CpG}$ islands in different studies. So far there is no systematic study comparing the significance of different $\mathrm{CpG}$ islands for protein expression. Despite the high frequency of hypermethylated tumors DAPK is not included in the CIMP phenotype gene panel.

DAPK can be transcriptionally inhibited by the pro-inflammatory transcription factors STAT3 and NFKB $(16,31,32)$. In addition, DAPK mRNA expression can be triggered by p53 (33), C/EBP- $\beta$ (34), HSF1 (35), and SMAD (36). Whereas $\mathrm{C} / \mathrm{EBP}-\beta$ binding depends on IFN $\gamma$ exposure, the binding of SMAD to the corresponding motifs is triggered by TGF- $\beta$. In general, DAPK might be upregulated transcriptionally in response to DNA damage $(21,37)$.

Jin and Gallagher (38) identified a second DAPK transcript that is alternatively spliced via intron retention which leads to the inclusion of a new stop codon downstream. Therefore, the alternative transcript is extended by $30 \mathrm{bp}$. Of note, both transcripts encode proteins with different cellular functions whereby DAPK $\alpha$ (classical DAPK1) is pro-apoptotic and DAPK $\beta$ is pro-survival.

Recently, miRNAs (miR-103, miR-107) have been identified to target DAPK 3'UTR. High miR-103 and miR-107 expression was correlated with high level of metastases and poor survival in colorectal cancer patients which is in agreement with DAPK's role as a metastasis suppressor (13). A data base search in silico predicted also some additional miRNAs that might play a role in DAPK regulation (21). However, experimental evidence for these miRNAs is lacking.

The stability of DAPK is regulated post-translationally by two different intracellular proteolysis systems (Table III). One is the ubiquitin proteasome system with HSC70-interacting protein (CHIP) that forms the complex between DAPK and HSP90 (39), DIP1 that interacts with the ankyrin repeat domain of DAPK (40) or the KLHL20 protein that acts as an adaptor for Cullin3-based E3-ligases and interacts with the death domain of DAPK (41). Several reports show that selective mechanisms exist for reducing cellular DAPK levels by directed targeting degradation of active DAPK (39). The other degradation system is the autophagocytic/lysosomal system. Here, the tuberous sclerosis complex (TSC) formed by its two proteins TSC1 (hamartin) and TSC2 (tuberin) inhibits the activation of mammalian target of rapamycin complex 1 (mTOR). Binding of the death domain to TSC2 leads either to phosphorylation of TSC2 by DAPK, a dissociation of the complex and mTOR activation or a reduction in DAPK levels directly by TSC2 via a post-translational mechanism (42). Finally, there is a non-ubiquitin, non-autophagic pathway for DAPK regulation which is dependent on cathepsin $\mathrm{B}$. Cathepsin $\mathrm{B}$ binds to $\mathrm{C}$-terminus region between the cytoskeleton-binding 
Table II. DAPK family - interaction partners of DRP-1, ZIPK, DRAK1 and DRAK2.

\begin{tabular}{|c|c|c|}
\hline Protein & Description & Interacting kinase \\
\hline RAD1 & Cell cycle checkpoint protein RAD1 & DRP-1,ZIPK, DRAK1, DRAK2 \\
\hline HORMAD1 & HORMA domain containing protein 1 & \\
\hline HORMAD2 & HORMA domain containing protein 1 & \\
\hline MAPK1 & Mitogen-activated protein kinase 1 & DRP-1, ZIPK \\
\hline MAPK3 & Mitogen-activated protein kinase 3 & \\
\hline RAB3IP & RAB3A interacting protein & \\
\hline MAP2K1 & Mitogen-activated protein kinase kinase 1 & \\
\hline UBC & ubiquitin $\mathrm{C}$ & ZIPK, DRAK1 \\
\hline MAP2K2 & Mitogen-activated protein kinase kinase 2 & \\
\hline RHOV & Ras homolog family member $\mathrm{V}$ & DRAK1, DRAK2 \\
\hline MLC1 & Megalencephalic leukoencephalopathy with subcortical cysts 1 & DRP-1 \\
\hline TGFBR1 & Transforming growth factor, $\beta$ receptor 1 & \\
\hline CSNK1A1 & Casein kinase $1, \alpha 1$ & \\
\hline CSNK1E & Casein kinase $1, \varepsilon$ & \\
\hline NKD1 & Naked cuticle homolog 1 (Drosophila) & \\
\hline DAPK2 & Death-associated protein kinase 2, DRP-1 & \\
\hline CAMK2A & Calcium/calmodulin-dependent protein kinase II $\alpha$ & \\
\hline MAP2K5 & Mitogen-activated protein kinase kinase 5 & \\
\hline DAXX & Death-domain associated protein & ZIPK \\
\hline ATF4 & Activating transcription factor 4 & \\
\hline AATF & Apoptosis antagonizing transcription factor & \\
\hline PRKCZ & Protein kinase $\mathrm{C}$, zeta & \\
\hline UBE2D3 & Ubiquitin-conjugating enzyme E2D 3 & \\
\hline MET & Hepatocyte growth factor receptor, proto-oncogene C-Met & \\
\hline PAWR & PRKC apoptosis WT1 regulator protein & \\
\hline CDKN1A & Cyclin-dependent kinase inhibitor $1 \mathrm{~A}, \mathrm{p} 21$ & \\
\hline GRB14 & Growth factor receptor-bound protein 14 & \\
\hline TPM1 & Tropomyosin $1(\alpha)$ & \\
\hline UBE2D1 & Ubiquitin-conjugating enzyme E2D 1 & \\
\hline GRB2 & Growth factor receptor-bound protein 2 & \\
\hline STAT3 & Signal transducer and activator of transcription 3 & \\
\hline UBE2D2 & Ubiquitin-conjugating enzyme E2D 2 & \\
\hline DAPK3 & Death-associated protein kinase 3, ZIPK & \\
\hline IRF2BPL & Interferon regulatory factor 2 binding protein-like & \\
\hline TPM4 & Tropomyosin 4 & \\
\hline UNC5B & Unc-5 homolog B (C. Elegans) & \\
\hline GRIN1 & Glutamate receptor, Ionotropic, N-methyl D-aspartate 1 & \\
\hline UBE2D4 & Ubiquitin-conjugating enzyme E2D 4 & \\
\hline AK3 & Adenylate kinase 3 & \\
\hline RPL34 & Ribosomal protein L34 & \\
\hline TCP10L & T-complex 10-Like & \\
\hline RAD21 & RAD21 homolog (S. Pombe) & \\
\hline PSMC3IP & PSMC3 interacting protein & \\
\hline ATM & Ataxia telangiectasia mutated & \\
\hline ULK3 & Unc-51 like kinase 3 & \\
\hline HDAC3 & Histone deacetylase 3 & DRAK1 \\
\hline CHP1 & Calcineurin-like EF-hand protein 1 & DRAK2 \\
\hline RPS24 & Ribosomal protein S24 & \\
\hline CHEK2 & Checkpoint kinase 2 & \\
\hline
\end{tabular}


Table III. DAPK substrates.

\begin{tabular}{|c|c|c|}
\hline Protein & OMIM ID & $\begin{array}{l}\text { Phosphorylation consensus site } \\
\text { (Consensus: KRxxxxxKRRxxS/T) }\end{array}$ \\
\hline Beclin-1 & 604378 & RLKVT ${ }^{119} \mathrm{GDL}$ \\
\hline $\mathrm{CaM}$ & 114180 & GSRREERSLS ${ }^{115} \mathrm{APG}$ \\
\hline MCM3 & 602693 & TKKTIERRYS ${ }^{160}$ DLTTL \\
\hline MLC & 609211 & TTKKRPQRATS ${ }^{19} \mathrm{NVF}$ \\
\hline $\mathrm{p} 21$ & 116899 & RKRRQT ${ }^{145}$ SMTDFYHSK \\
\hline p53 & 191170 & PPLSQET $^{18} \mathrm{FS}^{20}{ }^{20} \mathrm{WKLL}$ \\
\hline S6 & 180460 & QIAKRRRLS ${ }^{235}$ SLRAS \\
\hline Syntaxin-1A & 186590 & IIMDSSIS ${ }^{188}$ KQALSEIE \\
\hline Tau (MAPT) & 157140 & (1) \\
\hline Tropomyosin-1 & 191010 & HALNDMTS $^{283} \mathrm{I}$ \\
\hline ZIPK (DAPK3) & 603289 & 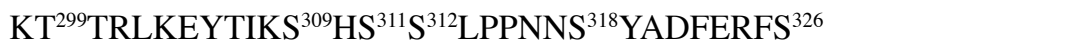 \\
\hline HSF-1 & 140580 & YSRQFS $^{230}$ LE ...DERPLS $^{290}$ SS ...PGRPSS ${ }^{320}$ VD ...RGHT ${ }^{355}$ DTEGRPPS $^{363} \mathrm{PP}$ \\
\hline
\end{tabular}

Mentioned indications are summarized from Stevens et al (28), Bialik and Kimchi (4), Benderska and Schneider-Stock (1), and Ivanovska et al (2). Bold, Inflammation-associated interaction partners of DAPK.

domain and the death domain and leads to a decrease in DAPK expression (43).

\section{DAPK interactome and substrates}

In addition to the multitude of DAPK upstream regulators controlling its catalytic activity via phosphorylation events and also its structural stability as mentioned above, further DAPK-binding proteins grouped as the DAPK interactome have been discovered (44) (Tables I and III). Only the minority of these interaction partners has been identified to be DAPK substrates. Thus, it is assumed that the specific binding of these proteins itself to certain consensus DAPK phosphorylation motifs (45) might be sufficient to trigger functional DAPK signaling. Effects of binding of CaM, cathepsin B, DIP1, Hsp90, LAR, Src, TSC2 and UNC5H2 to DAPK were discussed above.

Localized to the actin cytoskeleton, DAPK prominently interacts with cytoskeleton-associated proteins. In 2010 , Ivanovska et al found first that DAPK has a scaffold function to the LIMK/cofilin complex under TNF treatment which indicates a novel cytoskeleton-associated mechanism of TNF-induced DAPK-dependent actin remodeling and apoptosis in colorectal cancer cells (2). Henshall et al demonstrated that the interaction of actin and TNFR-1 with DAPK in rat brain is involved in the recruitment of DAPK to cell death signaling complexes including TNFR-1 and another DAPK interaction partner FADD (46). Actin binding was shown to cause structural rearrangement of microfilaments. Further on, they suggest that 14-3-3 binding modifies DAPK effects in epileptic brain injury. MAP1B was identified as a positive cofactor in DAPK-mediated autophagy including vesicle formation and membrane blebbing. In addition, beclin-1 activation by DAPK and further protein-protein interaction also was found to trigger autophagy (47). ERK enhances deathpromoting effects by DAPK Ser735 phosphorylation (48) whereas Ser289 phosphorylation by RSK has a reducing effect on apoptotic activity of DAPK (49). Targeted by PKD, DAPK was found to mediate JNK signaling and caspaseindependent cell death upon oxidative stress (50). ZIPK and DAPK were shown to functionally cooperate in causing cell death (51).

A list of DAPK interacting partners and DAPK substrates with consensus DAPK motif ( $\mathrm{RxxS} / \mathrm{T}$ and $\mathrm{KR} / \mathrm{R} \times \mathrm{SS} / \mathrm{T})$ is given in Tables I and III. It has to be mentioned that the prediction of DAPK substrates based only on phosphorylation sites is not a sufficient tool since some phosphorylation sites do not represent the specific DAPK motif. Nevertheless, the following proteins have been verified to be DAPK substrates: MLC and tropomyosin-1, MCM3, CaM, P21, P53, S6, Syntaxin-1A (52-58), TAU (MAPT) (27). MLC, ZIPK, Beclin1, HSF1, and tropomyosin-1 link DAPK to cell death associated membrane blebbing, cell motility and stress fiber formation $(52,53)$.

\section{Immunology and inflammatory responses associated with IBD}

Inflammatory bowel diseases (IBD) comprise a heterogeneous set of gastrointestinal (GI) tract disorders which are grouped into two major entities, namely CD and UC $(59,60)$. IBD typically affect children and young adults and the chronically relapsing inflammation of the GI-tract can cause a high individual and socioeconomic disease burden for people suffering from IBD. Despite considerable progress in IBD therapy during the past years, treatment options are still limited and all potent therapeutics bear the risk of relevant side effects, e.g. by suppressing immune effector functions resulting in increased susceptibility to infections.

The precise etiology of IBD has not been clarified yet, but it is well accepted that multiple factors are involved in the pathogenesis. Both CD and UC are characterized by dysregulated 
immune-responses in genetically predisposed individuals influenced by the microbiome and additional environmental cues $(59,60)$. In addition, defects of the intestinal epithelial barrier might precede and influence the onset of IBD (61).

Recent genetic and immunological investigations have revealed important insights into molecular players involved in the pathogenesis of IBD (62). Genome-wide association studies (GWAS) have linked susceptibility to IBD with single nucleotide polymorphisms (SNP) at more than 150 gene loci which are markedly enriched in genes involved in primary immunodeficiency as well as immune-mediated diseases (63). The contribution of a single risk locus to the individual's IBD risk appears low, and the majority of these loci is shared by both UC and CD.

Various innate and adaptive immune cells including macrophages, $\mathrm{T}$ effector cells, regulatory $\mathrm{T}$ cells or innate lymphoid cells have been implicated in intestinal inflammation and IBD pathogenesis (62-64). Moreover, current IBD therapies are primarily directed against imbalanced immune responses in IBD patients with strategies targeting the expansion and/or homing of pro-inflammatory $\mathrm{T}$ cell lymphocytes and the T cell-macrophage axis $(59,60,65-67)$. Notably, DAPK is well-known for being involved in modulating pro- and antiinflammatory immune responses in macrophage and $\mathrm{T}$ cell studies suggesting a potential role in IBD (68).

There is also growing evidence that defects of the intestinal epithelial barrier may trigger and influence intestinal inflammation in IBD patients (61). Noteworthy, we were able to demonstrate that DAPK can act as negative regulator of STAT3 in IECs suggesting an important role for DAPK in barrier function and potentially during IBD pathogenesis (16).

Cytokines are central players of the immunological crosstalk between different lamina propria cells and they can also shape barrier function by signaling from immune cell subsets to the intestinal epithelium $(69,70)$. It is well-known that the expression of multiple cytokines is elevated in the intestine during ongoing gut inflammation $(59,60,64)$. In addition, functional studies in experimental models have revealed that cytokines can potently influence the course of intestinal inflammation $(59,60,64)$. Such studies are further supported by genetic evidence from GWAS in IBD patients correlating single nucleotide polymorphisms with DNA loci containing genes associated with cytokine signaling (63).

Tumor necrosis factor alpha $(\mathrm{TNF}-\alpha)$ is a pro-inflammatory key molecule promoting the perpetuation of chronic intestinal inflammation in IBD, and anti TNF- $\alpha$ therapies are potent treatment options within current IBD-therapies for a substantial portion of IBD patients $(59,60,71)$. Of note, several studies reported that DAPK is crosslinked with TNF-receptor signaling and $\mathrm{NF}-\kappa \mathrm{B}$ activation providing further evidence for a potential therapeutic importance of DAPK in IBD. However, it was demonstrated that DAPK can process apparently opposing roles when either inhibiting or promoting inflammation $(16,35,68,72-74)$. Thus, further analyses with careful characterization of cell type specific actions and context-dependent influences are needed before DAPK might be considered a therapeutic target candidate in IBD. Besides TNF- $\alpha$, several other pro-inflammatory cytokines have been associated with intestinal inflammation (64). Some of them such as IL-1 $\beta$, IL-6, IL-17 and IL-18 are also known to be modulated by DAPK (16,75-77). In addition, DAPK is required for the formation of the NLRP3 inflammasome which is a key regulator for the expression of pro-inflammatory cytokines including IL-1 $\beta$ and IL-18 by macrophages and has been linked to IBD $(75,78,79)$.

TGF- $\beta$ receptor signaling is another pathway that seems to play a critical role in IBD. Notably, there is evidence that chronic intestinal inflammation in IBD patients is perpetuated by $\mathrm{T}$ effector cells expressing high levels of SMAD7 rendering them less susceptible towards suppression by regulatory T cells and TGF- $\beta$ signaling (80). Moreover, SMAD7 inhibition by antisense oligonucleotides has evolved as promising therapeutic strategy in patients with CD (81). DAPK is also connected to TGF- $\beta$ signal transduction via other SMADprotein family members $(63,82,83)$.

Thus, several lines of evidence suggest that targeting DAPK might influence the course of intestinal inflammation via modulation of immune cell activity and intestinal epithelial barrier function (Fig. 2). However, direct evidence for a critical role of DAPK is limited so far indicating the need for further studies investigating the cell type specific function of DAPK during intestinal inflammation.

\section{Link of IBD and cancer}

DAPK is involved in several forms of cell death including apoptosis, autophagy and anoikis suggesting a potential role in colitis-associated cancer (CAC) $(44,84)$. Although DAPK is often considered a tumor suppressor, pro-survival roles have also been reported $(44,84)$. In particular, there is evidence that DAPK might exert divergent functions under inflammatory conditions $(15,16)$.

IBD patients with longstanding inflammation of the colon are at increased risk for CRC (85). This risk is associated with the duration and anatomic extent of colitis and presence of other inflammatory diseases such primary sclerosing cholangitis (86-88). In fact, recommendations for colon cancer screening (time of initial screening colonoscopy and surveillance intervals) in IBD patients are stricter than for the general population (89).

CRC can be grouped into different entities with sporadic $\mathrm{CRC}$ being the most frequent subtype. IBD patients including UC patients as well as CD patients with colonic involvement are particular prone to $\mathrm{CAC}$ which can differ from classical sporadic CRC in various features. Sporadic CRC classically develops from normal mucosa via adenomatous polyps to CRC spanning over many years undergoing the adenoma - carcinoma sequence by accumulating sequential gene alterations including APC, KRAS and p53 (90-92). In CAC, similar genetic alterations are found, but a different order of hits including early p53 mutations could pave the way for direct progression to CAC skipping the stage of adenomatous precursor lesions $(93,94)$. CAC can show typical morphological features including flat tumor growth from multiple foci (90). Previous work reported positive feedback mechanisms between DAPK and p53 indicating potential functional relevance of DAPK for CAC growth control $(33,95)$. In addition, our studies have provided direct evidence for the interaction of DAPK with p38 MAPK and STAT3 signaling in inflammation-associated colorectal cancer cells $(14,16)$. 


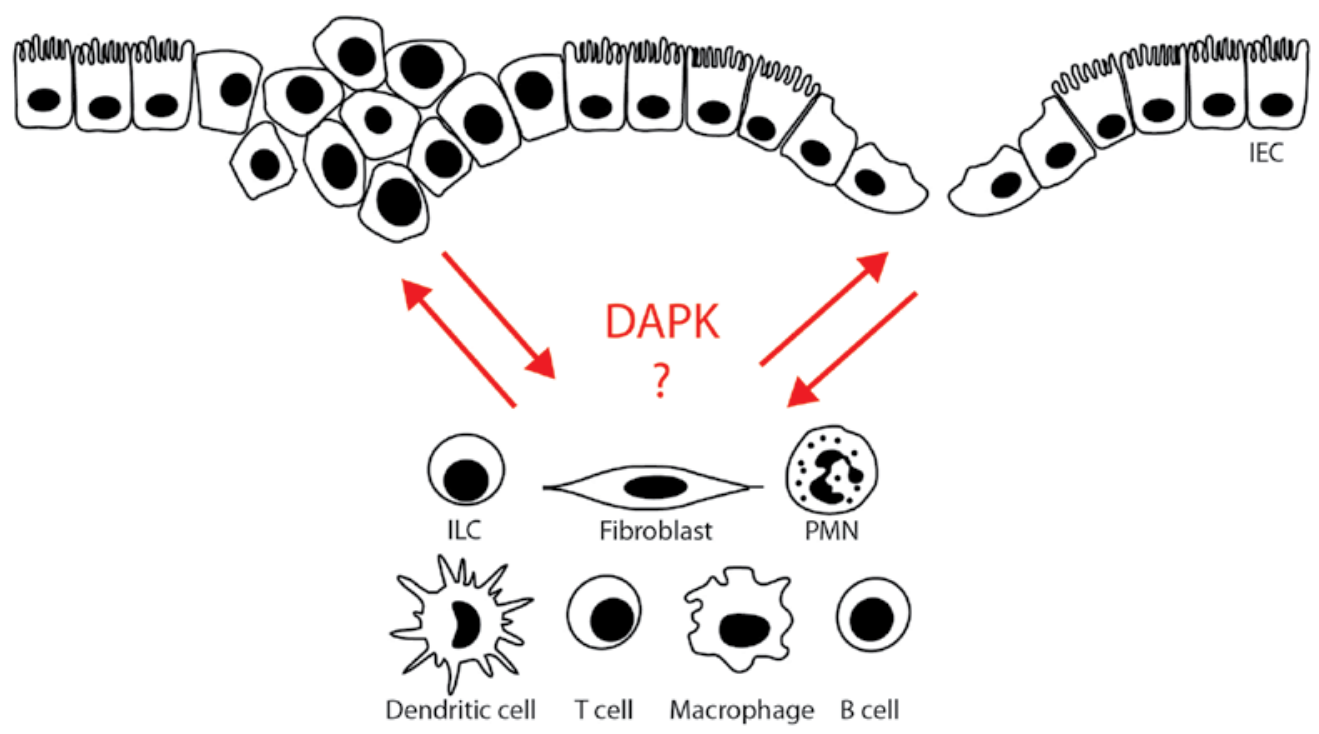

Figure 2. DAPK can be expressed by various cell types including intestinal epithelial cells (IECs) as well as innate and adaptive immune cells typically populating the gut in inflammatory bowel disease (IBD) and colitis-associated cancer (CAC). Further studies are needed to reveal context dependent contributions of DAPK in intestinal cell types potentially modulating the course of intestinal inflammation and/or CAC. Innate lymphoid cell (ILC), polymorphonuclear cells $(\mathrm{PMN})$.

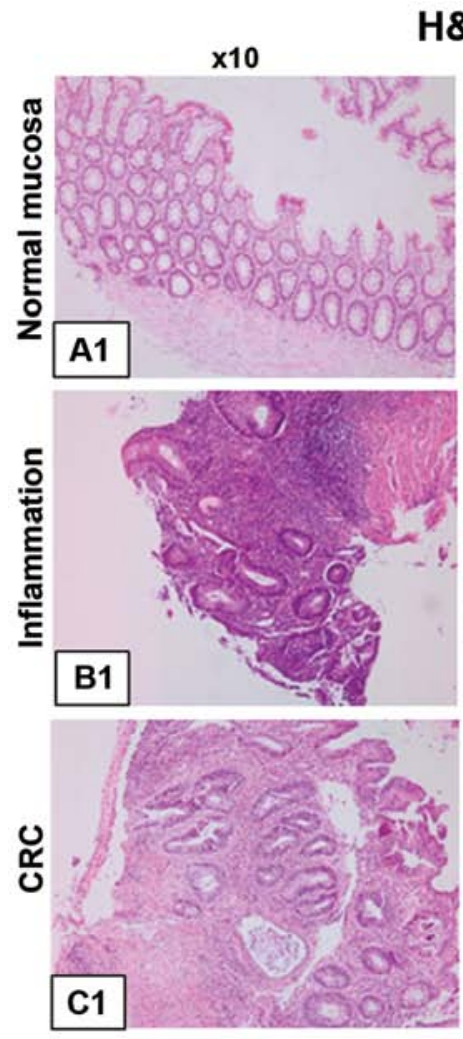

H\&E
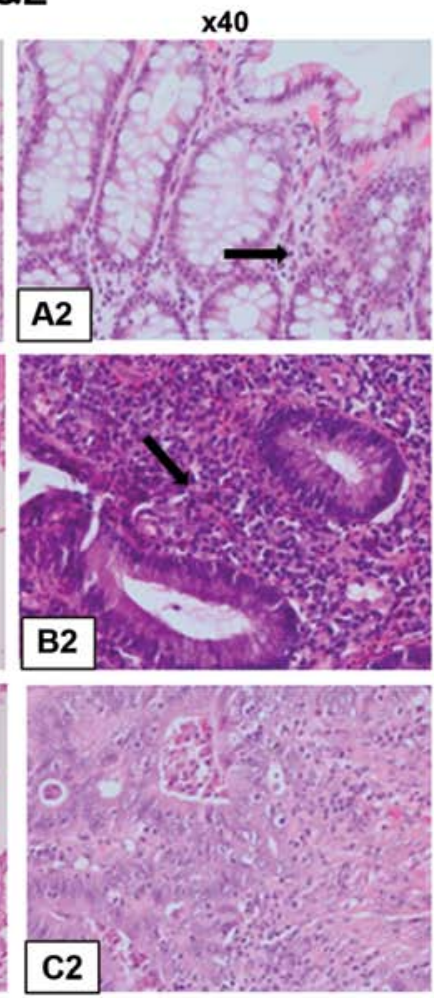

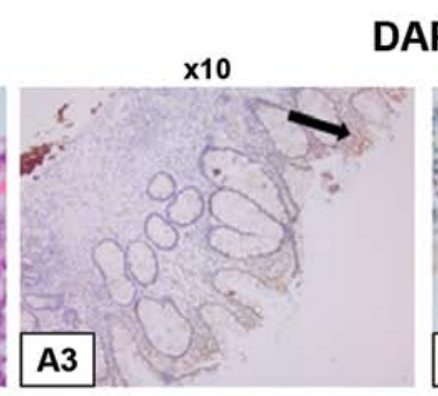

APK
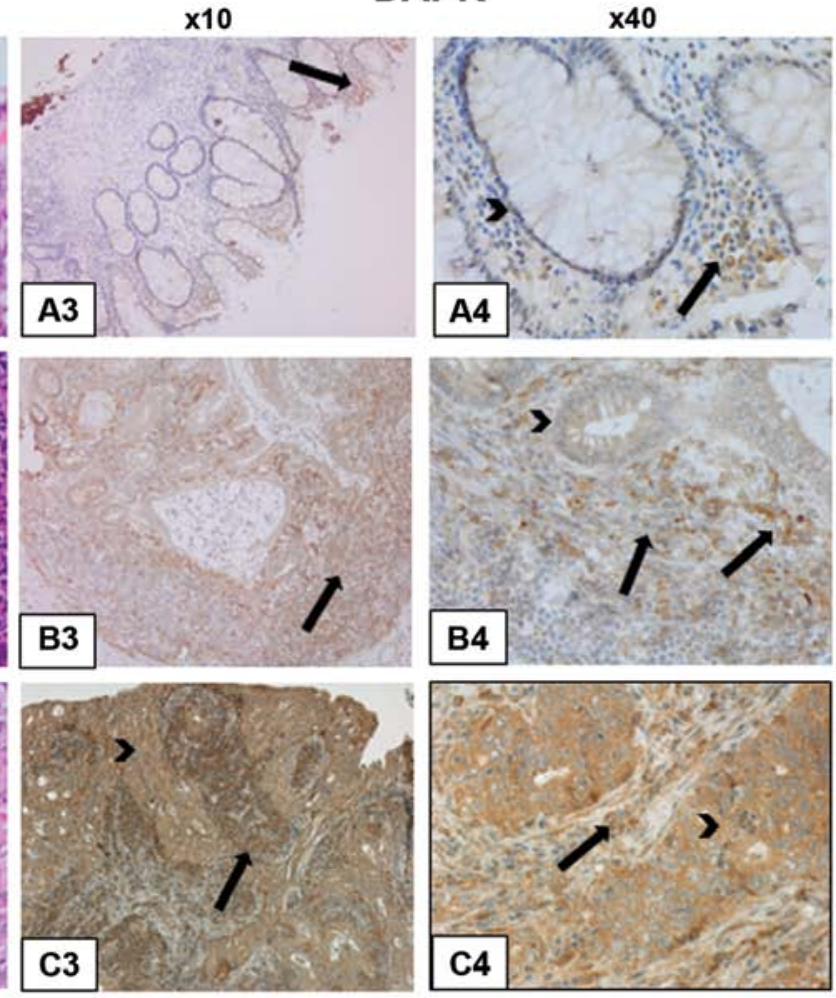

Figure 3. DAPK expression in inflammation (x10 and x40 fold magnification) (A1 and A2) Example of regular mucosa of the colon with mild inflammation $(\mathrm{H} \& \mathrm{E}, \rightarrow)$. (A3 and A4) Diffuse expression of DAPK in the cytoplasm of lymphocytes, plasma cells and macrophages in the interstitium. $(\rightarrow)$ and loss of expression in epithelial cells of colon mucosa (૪). (B1 and B2) Example of severe colitis with crypt architectural distorsion and chronic as well as acute inflammatory cells $(\mathrm{H} \& \mathrm{E}, \rightarrow)$. (B3 and B4) Strong expression of DAPK in the cytoplasm of inflammatory cells $(\rightarrow)$. Mild expression in epithelial cells of colon mucosa ( $)$. (C1 and C2) Example of colorectal carcinoma with intratumoral inflammatory reaction. (C3 and C4) Strong expression of DAPK in the cytoplasm of both, inflammatory cells $(\rightarrow)$ and tumor cells $(>)$.

The composition of the local microenvironment can further influence the tumor development. Of note, elevated levels of inflammatory cytokines and growth factors are typically found in CAC allowing for tumor growth promotion in 
experimental CAC models (96-99). As DAPK modulates the expression and/or signaling of some of these molecules such as IL-1 $\beta$ and IL-18, it is tempting to speculate that DAPK might also influence CAC development by interfering with the proinflammatory cytokine signaling. Moreover, elevated levels of reactive oxygen and nitrogen species typically found with chronic inflammation could further promote DNA damage and DAPK expression during CAC development $(21,100)$.

As in sporadic CRC, epigenetic alterations are often present in CAC and may influence tumor development. DAPK belongs to the genes that are frequent targets of hypermethylation in $\mathrm{CRC}$, and aberrant methylation of DAPK in long-standing UC and CAC was demonstrated $(15,101)$.

In summary, several findings suggest that DAPK could modify molecular mechanisms of colitis-associated tumorigenesis. To date however, it has not been clarified which particular context is critical for rendering DAPK1 either a tumor suppressor or oncogenic molecule in tumor epithelial and/or tumor stromal cells. Upcoming analyses could provide important functional insights and might put DAPK1 on stage as a target for CAC therapy.

\section{DAPK regulation and function in different cell types of the intestine}

The role of DAPK in the intestine has not been sufficiently elucidated so far. DAPK is expressed and can be activated by numerous cell types including intestinal epithelial cells (IECs) as well as innate and adaptive immune cells typically populating the gut such as macrophages and $\mathrm{T}$ cells, respectively. The immunohistochemical DAPK expression in single stages of UC-associated carcinogenesis in regard to different cell types is demonstrated exemplarily in Fig. 3.

Several studies point to a complicated regulatory role of DAPK in IECs $(15,16)$. Noteworthy, DAPK expression in IECs is increased in long-standing UC and correlates with the activity of UC-associated inflammation suggesting a protective role of DAPK during the chronic inflammatory process of UC (15). In addition, DAPK protein expression is elevated in CAC, which may potentially link DAPK to the initiation of the neoplastic process in CAC (15). Remarkably, recent work provided further evidence for a substantial role of DAPK in modulating epithelial cell function (16). In fact, it was demonstrated that STAT3 and DAPK are upregulated in UC but only STAT3 is downregulated in CAC. In addition, DAPK was identified to suppress TNF-induced STAT3 activation and a direct physical interaction of DAPK with STAT3 inducing conformational changes in the STAT3 dimer was proposed as molecular cause (16). Thus, DAPK can act as negative regulator of STAT3 in IECs suggesting an important role for barrier function and regulation of the intestinal homeostasis upon inflammatory stimuli and cancer (16).

DAPK-positive tumor-associated macrophages have been localized in close proximity with apoptotic colorectal cancer cells suggesting direct crosstalk between macrophages and tumor epithelial cells in the intestine (102). Based on studies with purified primary leukocytes and immune cell lines, DAPK might also be involved in the functional regulation of immune cell populations during chronic intestinal inflammation (68). For macrophages, inhibition of inflammation was shown via IFN- $\gamma$ activated inhibitor of translation (GAIT) complex (103). In addition, macrophages can produce a variety of pro-inflammatory cytokines that are partly controlled by DAPK, e.g. via functional assembly of the NLRP3 inflammasome and activation of caspase-1 (75).

In the adaptive arm of the immune system, DAPK was shown to block the nuclear translocation of ERK1/2 in T lymphocytes (104). Further work demonstrated decreased $\mathrm{T}$ cell proliferation and IL-2 production upon stimulation by the $\mathrm{T}$ cell receptor (74) indicating that DAPK can interfere with $\mathrm{T}$ cell activation which might have important implications for chronic inflammatory diseases such as IBD.

Thus, several pieces of evidence suggest potential contributions of DAPK in the regulation of gut inflammation and intestinal homeostasis. However, further studies are needed to clarify the dominant effects of DAPK in different innate and adaptive immune cell subsets as well as non-immune cells populating the bowel wall during chronic gut inflammation.

\section{Open questions and future challenges}

Regarding direct evidence for a role of DAPK in intestinal inflammation there are many open questions: Which immune cells in the intestinal lamina propria are controlled by DAPK? Are there differential effects on subsets of T helper cell populations including Th1, Th17, and regulatory T cells? What is the role of DAPK in B cells? Are there different effects on macrophage subsets including M1 and M2 macrophages? Which role does DAPK play in non-immune stromal cells such as fibroblasts? How does DAPK interact with signals from the microbiome?

Providing answers to the above questions may help in better understanding of how DAPK controls the function of gut cell populations associated with the pathogenesis of IBD and CRC (Fig. 2). Perspectively, novel insights into molecular disease mechanisms and potential key checkpoints might facilitate the design of new therapeutic approaches for IBD and CRC. Therefore, further studies are awaited that directly reveal the role of DAPK in intestinal homeostasis, intestinal inflammation and CRC.

\section{Acknowledgements}

The authors would like to thank the Interdisciplinary Center of Clinical Research (IZKF) at the University Clinics Erlangen (project D21 to R.S.-S. and C.N.), the Emerging Fields Initiative at the FAU Erlangen-Nürnberg (to C.N. and R.S.-S.), and the Deutsche Forschungsgemeinschaft (DFG grant Ne1927 to C.N.) for financial support.

\section{References}

1. Schneider-Stock R: Death-associated kinase (DAPK): a cancer 'gene chameleon'. Apoptosis 19: 285, 2014.

2. Ivanovska J, Tregubova A, Mahadevan V, Chakilam S, Gandesiri M, Benderska N, Ettle B, Hartmann A, Söder S, Ziesché E, et al: Identification of DAPK as a scaffold protein for the LIMK/cofilin complex in TNF-induced apoptosis. Int J Biochem Cell Biol 45: 1720-1729, 2013.

3. Cohen O, Inbal B, Kissil JL, Raveh T, Berissi H, SpivakKroizaman T, Feinstein E and Kimchi A: DAP-kinase participates in TNF-alpha- and Fas-induced apoptosis and its function requires the death domain. J Cell Biol 146: 141-148, 1999. 
4. Bialik S and Kimchi A: The death-associated protein kinases: Structure, function, and beyond. Annu Rev Biochem 75: 189-210, 2006.

5. Gautel M: Cytoskeletal protein kinases: Titin and its relations in mechanosensing. Pflugers Arch 462: 119-134, 2011.

6. Brenner H, Kloor M and Pox CP: Colorectal cancer. Lancet 383: 1490-1502, 2014

7. Wu WK, Wang XJ, Cheng AS, Luo MX, Ng SS, To KF, Chan FK, Cho $\mathrm{CH}$, Sung JJ and Yu J: Dysregulation and crosstalk of cellular signaling pathways in colon carcinogenesis. Crit Rev Oncol Hematol 86: 251-277, 2013.

8. Jass JR: Classification of colorectal cancer based on correlation of clinical, morphological and molecular features. Histopathology 50: 113-130, 2007

9. Draht MX, Riedl RR, Niessen H, Carvalho B, Meijer GA, Herman JG, van Engeland M, Melotte V and Smits KM: Promoter $\mathrm{CpG}$ island methylation markers in colorectal cancer: The road ahead. Epigenomics 4: 179-194, 2012.

10. Feagins LA, Souza RF and Spechler SJ: Carcinogenesis in IBD Potential targets for the prevention of colorectal cancer. Nat Rev Gastroenterol Hepatol 6: 297-305, 2009.

11. Itzkowitz SH and Yio X: Inflammation and cancer IV. Colorectal cancer in inflammatory bowel disease: The role of inflammation. Am J Physiol Gastrointest Liver Physiol 287: G7-G17, 2004.

12. Mittag F, Kuester D, Vieth M, Peters B, Stolte B, Roessner A and Schneider-Stock R: DAPK promotor methylation is an early event in colorectal carcinogenesis. Cancer Lett 240: 69-75, 2006.

13. Chen HY, Lee YR and Chen RH: The functions and regulations of DAPK in cancer metastasis. Apoptosis 19: 364-370, 2014.

14. Bajbouj K, Poehlmann A, Kuester D, Drewes T, Haase K, Hartig R, Teller A, Kliche S, Walluscheck D, Ivanovska J, et al: Identification of phosphorylated p38 as a novel DAPK-interacting partner during TNFalpha-induced apoptosis in colorectal tumor cells. Am J Pathol 175: 557-570, 2009.

15. Kuester D, Guenther T, Biesold S, Hartmann A, Bataille F, Ruemmele P, Peters B, Meyer F, Schubert D, Bohr UR, et al: Aberrant methylation of DAPK in long-standing ulcerative colitis and ulcerative colitis-associated carcinoma. Pathol Res Pract 206: 616-624, 2010.

16. Chakilam S, Gandesiri M, Rau TT, Agaimy A, Vijayalakshmi M, Ivanovska J, Wirtz RM, Schulze-Luehrmann J, Benderska N, Wittkopf N, et al: Death-associated protein kinase controls STAT3 activity in intestinal epithelial cells. Am J Pathol 182: 1005-1020, 2013

17. Kawai T, Matsumoto M, Takeda K, Sanjo H and Akira S: ZIP kinase, a novel serine/threonine kinase which mediates apoptosis. Mol Cell Biol 18: 1642-1651, 1998.

18. Kögel D, Plöttner O, Landsberg G, Christian S and Scheidtmann KH: Cloning and characterization of Dlk, a nove serine/threonine kinase that is tightly associated with chromatin and phosphorylates core histones. Oncogene 17: 2645-2654, 1998

19. Inbal B, Shani G, Cohen O, Kissil JL and Kimchi A: Deathassociated protein kinase-related protein 1, a novel serine/ threonine kinase involved in apoptosis. Mol Cell Biol 20 1044-1054, 2000

20. Kawai T, Nomura F, Hoshino K, Copeland NG, Gilbert DJ, Jenkins NA and Akira S: Death-associated protein kinase 2 is a new calcium/calmodulin-dependent protein kinase that signals apoptosis through its catalytic activity. Oncogene 18: 3471-3480, 1999.

21. Benderska N and Schneider-Stock R: Transcription control of DAPK. Apoptosis 19: 298-305, 2014.

22. Dagher R, Peng S, Gioria S, Fève M, Zeniou M, Zimmermann M, Pigault C, Haiech J and Kilhoffer MC: A general strategy to characterize calmodulin-calcium complexes involved in CaM-target recognition: DAPK and EGFR calmodulin binding domains interact with different calmodulin-calcium complexes. Biochim Biophys Acta 1813: 1059-1067, 2011.

23. de Diego I, Kuper J, Bakalova N, Kursula P and Wilmanns M: Molecular basis of the death-associated protein kinase-calcium/ calmodulin regulator complex. Sci Signal 3: ra6, 2010.

24. Wang WJ, Kuo JC, Ku W, Lee YR, Lin FC, Chang YL, Lin YM, Chen $\mathrm{CH}$, Huang YP, Chiang MJ, et al: The tumor suppressor DAPK is reciprocally regulated by tyrosine kinase Src and phosphatase LAR. Mol Cell 27: 701-716, 2007.

25. Bialik S and Kimchi A: Biochemical and functional characterization of the ROC domain of DAPK establishes a new paradigm of GTP regulation in ROCO proteins. Biochem Soc Trans 40: 1052-1057, 2012.
26. Carlessi R, Levin-Salomon V, Ciprut S, Bialik S, Berissi H, Albeck S, Peleg Y and Kimchi A: GTP binding to the ROC domain of DAP-kinase regulates its function through intramolecular signalling. EMBO Rep 12: 917-923, 2011

27. Kim BM, You MH, Chen CH, Lee S, Hong Y, Hong Y, Kimchi A, Zhou XZ and Lee TH: Death-associated protein kinase 1 has a critical role in aberrant tau protein regulation and function. Cell Death Dis 5: e1237, 2014.

28. Stevens C, Lin Y, Harrison B, Burch L, Ridgway RA, Sansom O and Hupp T: Peptide combinatorial libraries identify TSC2 as a death-associated protein kinase (DAPK) death domain-binding protein and reveal a stimulatory role for DAPK in mTORC1 signaling. J Biol Chem 284: 334-344, 2009.

29. Kissil JL, Feinstein E, Cohen O, Jones PA, Tsai YC, Knowles MA Eydmann ME and Kimchi A: DAP-kinase loss of expression in various carcinoma and B-cell lymphoma cell lines: Possible implications for role as tumor suppressor gene. Oncogene 15: 403-407, 1997

30. Leung RC, Liu SS, Chan KY, Tam KF, Chan KL, Wong LC and Ngan HY: Promoter methylation of death-associated protein kinase and its role in irradiation response in cervical cancer. Oncol Rep 19: 1339-1345, 2008.

31. Shanmugam R, Gade P, Wilson-Weekes A, Sayar H, Suvannasankha A, Goswami C, Li L, Gupta S, Cardoso AA, Al Baghdadi T, et al: A noncanonical Flt3ITD/NF- $\kappa$ B signaling pathway represses DAPK1 in acute myeloid leukemia. Clin Cancer Res 18: 360-369, 2012.

32. Hayakawa J, Mittal S, Wang Y, Korkmaz KS, Adamson E, English C, Ohmichi M, McClelland M and Mercola D: Identification of promoters bound by c-Jun/ATF2 during rapid large-scale gene activation following genotoxic stress. Mol Cell 16: 521-535, 2004.

33. Martoriati A, Doumont G, Alcalay M, Bellefroid E, Pelicci PG and Marine JC: dapk1, encoding an activator of a p19ARFp53-mediated apoptotic checkpoint, is a transcription target of p53. Oncogene 24: 1461-1466, 2005.

34. Gade P, Roy SK, Li H, Nallar SC and Kalvakolanu DV: Critical role for transcription factor $\mathrm{C} / \mathrm{EBP}$-beta in regulating the expression of death-associated protein kinase 1. Mol Cell Biol 28: 2528-2548, 2008.

35. Benderska N, Ivanovska J, Rau TT, Schulze-Luehrmann J, Mohan S, Chakilam S, Gandesiri M, Ziesché E, Fischer T, Söder S, et al: DAPK-HSF1 interaction as a new positive feedback loop for TNF-induced apoptosis in colorectal cancer cells. J Cell Sci 127: 5273-5287, 2014.

36. Massagué J, Seoane J and Wotton D: Smad transcription factors. Genes Dev 19: 2783-2810, 2005

37. Gandesiri M, Chakilam S, Ivanovska J, Benderska N, Ocker M, Di Fazio P, Feoktistova M, Gali-Muhtasib H, Rave-Fränk M, Prante O, et al: DAPK plays an important role in panobinostatinduced autophagy and commits cells to apoptosis under autophagy deficient conditions. Apoptosis 17: 1300-1315, 2012.

38. Jin Y and Gallagher PJ: Antisense depletion of death-associated protein kinase promotes apoptosis. J Biol Chem 278: 51587-51593, 2003.

39. Zhang L, Nephew KP and Gallagher PJ: Regulation of death-associated protein kinase. Stabilization by HSP90 heterocomplexes. J Biol Chem 282: 11795-11804, 2007.

40. Jin Y, Blue EK, Dixon S, Shao Z and Gallagher PJ: A deathassociated protein kinase (DAPK)-interacting protein, DIP-1, is an E3 ubiquitin ligase that promotes tumor necrosis factorinduced apoptosis and regulates the cellular levels of DAPK. J Biol Chem 277: 46980-46986, 2002

41. Lee YR, Yuan WC, Ho HC, Chen CH, Shih HM and Chen RH: The Cullin 3 substrate adaptor KLHL20 mediates DAPK ubiquitination to control interferon responses. EMBO J 29: 1748-1761, 2010.

42. Gallagher PJ and Blue EK: Post-translational regulation of the cellular levels of DAPK. Apoptosis 19: 306-315, 2014.

43. Lin Y, Stevens C and Hupp T: Identification of a dominant negative functional domain on DAPK-1 that degrades DAPK-1 protein and stimulates TNFR-1-mediated apoptosis. J Biol Chem 282: 16792-16802, 2007

44. Lin Y, Hupp TR and Stevens C: Death-associated protein kinase (DAPK) and signal transduction: Additional roles beyond cell death. FEBS J 277: 48-57, 2010.

45. Benderska N, Chakilam S, Hugle M, Ivanovska J, Gandesiri M, Schulze-Luhrmann J, Bajbouj K, Croner R and Schneider-Stock R: Apoptosis signalling activated by TNF in the lower gastrointestinal tract--review. Curr Pharm Biotechnol 13: 2248-2258, 2012. 
46. Henshall DC, Araki T, Schindler CK, Shinoda S, Lan JQ and Simon RP: Expression of death-associated protein kinase and recruitment to the tumor necrosis factor signaling pathway following brief seizures. J Neurochem 86: 1260-1270, 2003.

47. Zalckvar E, Berissi H, Mizrachy L, Idelchuk Y, Koren I, Eisenstein M, Sabanay H, Pinkas-Kramarski R and Kimchi A: DAP-kinase-mediated phosphorylation on the $\mathrm{BH} 3$ domain of beclin 1 promotes dissociation of beclin 1 from Bcl-XL and induction of autophagy. EMBO Rep 10: 285-292, 2009.

48. Chen CH, Wang WJ, Kuo JC, Tsai HC, Lin JR, Chang ZF and Chen RH: Bidirectional signals transduced by DAPK-ERK interaction promote the apoptotic effect of DAPK. EMBO J 24: 294-304, 2005.

49. Anjum R, Roux PP, Ballif BA, Gygi SP and Blenis J: The tumor suppressor DAP kinase is a target of RSK-mediated survival signaling. Curr Biol 15: 1762-1767, 2005.

50. Eisenberg-Lerner A and Kimchi A: DAP kinase regulates JNK signaling by binding and activating protein kinase $\mathrm{D}$ under oxidative stress. Cell Death Differ 14: 1908-1915, 2007.

51. Shani G, Marash L, Gozuacik D, Bialik S, Teitelbaum L, Shohat G and Kimchi A: Death-associated protein kinase phosphorylates ZIP kinase, forming a unique kinase hierarchy to activate its cel death functions. Mol Cell Biol 24: 8611-8626, 2004

52. Kuo JC, Lin JR, Staddon JM, Hosoya $\mathrm{H}$ and Chen RH Uncoordinated regulation of stress fibers and focal adhesions by DAP kinase. J Cell Sci 116: 4777-4790, 2003.

53. Houle F, Poirier A, Dumaresq J and Huot J: DAP kinase mediates the phosphorylation of tropomyosin-1 downstream of the ERK pathway, which regulates the formation of stress fibers in response to oxidative stress. J Cell Sci 120: 3666-3677, 2007.

54. Bialik S, Berissi $\mathrm{H}$ and Kimchi A: A high throughput proteomics screen identifies novel substrates of death-associated protein kinase. Mol Cell Proteomics 7: 1089-1098, 2008.

55. Schumacher AM, Schavocky JP, Velentza AV, Mirzoeva S and Watterson DM: A calmodulin-regulated protein kinase linked to neuron survival is a substrate for the calmodulin-regulated deathassociated protein kinase. Biochemistry 43: 8116-8124, 2004.

56. Fraser JA and Hupp TR: Chemical genetics approach to identify peptide ligands that selectively stimulate DAPK-1 kinase activity. Biochemistry 46: 2655-2673, 2007.

57. Schumacher AM, Velentza AV, Watterson DM and Dresios J: Death-associated protein kinase phosphorylates mammalian ribosomal protein $\mathrm{S} 6$ and reduces protein synthesis. Biochemistry 45: 13614-13621, 2006.

58. Tian JH, Das S and Sheng ZH: $\mathrm{Ca}^{2+}$-dependent phosphorylation of syntaxin-1A by the death-associated protein (DAP) kinase regulates its interaction with Munc18. J Biol Chem 278 26265-26274, 2003.

59. Danese S and Fiocchi C: Ulcerative colitis. N Engl J Med 365: $1713-1725,2011$.

60. Baumgart DC and Sandborn WJ: Crohn's disease. Lancet 380: 1590-1605, 2012

61. Atreya R and Neurath MF: IBD pathogenesis in 2014: Molecular pathways controlling barrier function in IBD. Nat Rev Gastroenterol Hepatol 12: 67-68, 2014.

62. Strober W, Fuss I and Mannon P: The fundamental basis of inflammatory bowel disease. J Clin Invest 117: 514-521, 2007.

63. Jostins L, Ripke S, Weersma RK, Duerr RH, McGovern DP, Hui KY, Lee JC, Schumm LP, Sharma Y, Anderson CA, et al International IBD Genetics Consortium (IIBDGC): Hostmicrobe interactions have shaped the genetic architecture of inflammatory bowel disease. Nature 491: 119-124, 2012.

64. Neurath MF: Cytokines in inflammatory bowel disease. Nat Rev Immunol 14: 329-342, 2014.

65. Feagan BG, Rutgeerts $\mathrm{P}$, Sands BE, Hanauer S, Colombel JF, Sandborn WJ, Van Assche G, Axler J, Kim HJ, Danese S, et al GEMINI 1 Study Group: Vedolizumab as induction and maintenance therapy for ulcerative colitis. N Engl J Med 369: 699-710, 2013.

66. Sandborn WJ, Feagan BG, Rutgeerts P, Hanauer S, Colombel JF, Sands BE, Lukas M, Fedorak RN, Lee S, Bressler B, et al, GEMINI 2 Study Group: Vedolizumab as induction and maintenance therapy for Crohn's disease. N Engl J Med 369: 711-721, 2013.

67. Atreya R, Zimmer M, Bartsch B, Waldner MJ, Atreya I, Neumann H, Hildner K, Hoffman A, Kiesslich R, Rink AD, et al Antibodies against tumor necrosis factor (TNF) induce T-cell apoptosis in patients with inflammatory bowel diseases via TNF receptor 2 and intestinal $\mathrm{CD} 14^{+}$macrophages. Gastroenterology 141: 2026-2038, 2011.
68. Lai MZ and Chen RH: Regulation of inflammation by DAPK. Apoptosis 19: 357-363, 2014.

69. Backert I, Koralov SB, Wirtz S, Kitowski V, Billmeier U, Martini E, Hofmann K, Hildner K, Wittkopf N, Brecht K, et al: STAT3 activation in Th17 and Th22 cells controls IL-22mediated epithelial host defense during infectious colitis. J Immunol 193: 3779-3791, 2014.

70. Pickert G, Neufert C, Leppkes M, Zheng Y, Wittkopf $N$, Warntjen M, Lehr HA, Hirth S, Weigmann B, Wirtz S, et al: STAT3 links IL-22 signaling in intestinal epithelial cells to mucosal wound healing. J Exp Med 206: 1465-1472, 2009.

71. Atreya R, Neumann H, Neufert C, Waldner MJ, Billmeier U, Zopf Y, Willma M, App C, Münster T, Kessler H, et al: In vivo imaging using fluorescent antibodies to tumor necrosis factor predicts therapeutic response in Crohn's disease. Nat Med 20: 313-318, 2014

72. Jin Y, Blue EK and Gallagher PJ: Control of death-associated protein kinase (DAPK) activity by phosphorylation and proteasomal degradation. J Biol Chem 281: 39033-39040, 2006.

73. Yoo HJ, Byun HJ, Kim BR, Lee KH, Park SY and Rho SB: DAPk1 inhibits NF- $\kappa$ B activation through TNF- $\alpha$ and INF- $\gamma-$ induced apoptosis. Cell Signal 24: 1471-1477, 2012.

74. Chuang YT, Fang LW, Lin-Feng MH, Chen RH and Lai MZ: The tumor suppressor death-associated protein kinase targets to TCR-stimulated NF-kappa B activation. J Immunol 180: 3238-3249, 2008.

75. Chuang YT, Lin YC, Lin KH, Chou TF, Kuo WC, Yang KT, Wu PR, Chen RH, Kimchi A and Lai MZ: Tumor suppressor death-associated protein kinase is required for full IL- $1 \beta$ production. Blood 117: 960-970, 2011.

76. Turner-Brannen E, Choi KY, Arsenault R, El-Gabalawy H, Napper S and Mookherjee N: Inflammatory cytokines IL-32 and IL-17 have common signaling intermediates despite differential dependence on TNF-receptor 1. J Immunol 186: 7127-7135, 2011.

77. Nakav S, Cohen S, Feigelson SW, Bialik S, Shoseyov D, Kimchi A and Alon R: Tumor suppressor death-associated protein kinase attenuates inflammatory responses in the lung. Am J Respir Cell Mol Biol 46: 313-322, 2012

78. Bauer C, Duewell P, Mayer C, Lehr HA, Fitzgerald KA, Dauer M, Tschopp J, Endres S, Latz E and Schnurr M: Colitis induced in mice with dextran sulfate sodium (DSS) is mediated by the NLRP3 inflammasome. Gut 59: 1192-1199, 2010.

79. Schoultz I, Verma D, Halfvarsson J, Törkvist L, Fredrikson M, Sjöqvist U, Lördal M, Tysk C, Lerm M, Söderkvist P, et al: Combined polymorphisms in genes encoding the inflammasome components NALP3 and CARD8 confer susceptibility to Crohn's disease in Swedish men. Am J Gastroenterol 104: 1180-1188, 2009.

80. Fantini MC, Rizzo A, Fina D, Caruso R, Sarra M, Stolfi C, Becker C, Macdonald TT, Pallone F, Neurath MF and Monteleone G: Smad7 controls resistance of colitogenic T cells to regulatory T cell-mediated suppression. Gastroenterology 136: 1308-1316, e1-3, 2009.

81. Monteleone G, Fantini MC, Onali S, Zorzi F, Sancesario G, Bernardini S, Calabrese E, Viti F, Monteleone I, Biancone L and Pallone F: Phase I clinical trial of Smad7 knockdown using antisense oligonucleotide in patients with active Crohn's disease. Mol Ther 20: 870-876, 2012.

82. Jang CW, Chen CH, Chen CC, Chen JY, Su YH and Chen RH: TGF-beta induces apoptosis through Smad-mediated expression of DAP-kinase. Nat Cell Biol 4: 51-58, 2002.

83. MacDonald TT, Monteleone I, Fantini MC and Monteleone G: Regulation of homeostasis and inflammation in the intestine. Gastroenterology 140: 1768-1775, 2011.

84. Shiloh R, Bialik S and Kimchi A: The DAPK family: a structurefunction analysis. Apoptosis 19: 286-297, 2014.

85. Ekbom A, Helmick C, Zack M and Adami HO: Ulcerative colitis and colorectal cancer. A population-based study. N Engl J Med 323: 1228-1233, 1990

86. Mathy C, Schneider K, Chen YY, Varma M, Terdiman JP and Mahadevan U: Gross versus microscopic pancolitis and the occurrence of neoplasia in ulcerative colitis. Inflamm Bowel Dis 9: 351-355, 2003.

87. Rutter M, Saunders B, Wilkinson K, Rumbles S, Schofield G, Kamm M, Williams C, Price A, Talbot I and Forbes A: Severity of inflammation is a risk factor for colorectal neoplasia in ulcerative colitis. Gastroenterology 126: 451-459, 2004.

88. Broomé U, Lindberg G and Löfberg R: Primary sclerosing cholangitis in ulcerative colitis - a risk factor for the development of dysplasia and DNA aneuploidy? Gastroenterology 102: $1877-1880,1992$ 
89. Van Assche G, Dignass A, Bokemeyer B, Danese S, Gionchetti P, Moser G, Beaugerie L, Gomollón F, Häuser W, Herrlinger K, et al; European Crohn's and Colitis Organisation: Second European evidence-based consensus on the diagnosis and management of ulcerative colitis part 3: Special situations. J Crohn's Colitis 7: 1-33, 2013.

90. Ullman TA and Itzkowitz SH: Intestinal inflammation and cancer. Gastroenterology 140: 1807-1816, 2011

91. Vogelstein B, Fearon ER, Hamilton SR, Kern SE, Preisinger AC, Leppert M, Nakamura Y, White R, Smits AM and Bos JL: Genetic alterations during colorectal-tumor development. N Engl J Med 319: 525-532, 1988.

92. Fearon ER: Molecular genetics of colorectal cancer. Annu Rev Pathol 6: 479-507, 2011.

93. Hussain SP, Amstad P, Raja K, Ambs S, Nagashima M, Bennett WP, Shields PG, Ham AJ, Swenberg JA, Marrogi AJ, et al: Increased p53 mutation load in noncancerous colon tissue from ulcerative colitis: A cancer-prone chronic inflammatory disease. Cancer Res 60: 3333-3337, 2000.

94. Redston MS, Papadopoulos N, Caldas C, Kinzler KW and Kern SE: Common occurrence of APC and K-ras gene mutations in the spectrum of colitis-associated neoplasias. Gastroenterology 108: 383-392, 1995.

95. Michie AM, McCaig AM, Nakagawa R and Vukovic M: Deathassociated protein kinase (DAPK) and signal transduction: Regulation in cancer. FEBS J 277: 74-80, 2010.

96. Grivennikov S, Karin E, Terzic J, Mucida D, Yu GY, Vallabhapurapu S, Scheller J, Rose-John S, Cheroutre H, Eckmann L, et al: IL-6 and Stat3 are required for survival of intestinal epithelial cells and development of colitis-associated cancer. Cancer Cell 15: 103-113, 2009.

97. Neufert C, Becker C, Türeci Ö, Waldner MJ, Backert I, Floh K, Atreya I, Leppkes M, Jefremow A, Vieth M, et al: Tumor fibroblast-derived epiregulin promotes growth of colitis-associated neoplasms through ERK. J Clin Invest 123: 1428-1443, 2013.
98. Salcedo R, Worschech A, Cardone M, Jones Y, Gyulai Z, Dai RM, Wang E, Ma W, Haines D, O'hUigin C, et al: MyD88mediated signaling prevents development of adenocarcinomas of the colon: Role of interleukin 18. J Exp Med 207: 1625-1636, 2010.

99.Popivanova BK, Kitamura K, Wu Y, Kondo T, Kagaya T, Kaneko S, Oshima M, Fujii C and Mukaida N: Blocking TNF-alpha in mice reduces colorectal carcinogenesis associated with chronic colitis. J Clin Invest 118: 560-570, 2008.

100.D'Incà R, Cardin R, Benazzato L, Angriman I, Martines D and Sturniolo GC: Oxidative DNA damage in the mucosa of ulcerative colitis increases with disease duration and dysplasia. Inflamm Bowel Dis 10: 23-27, 2004.

101. Goel A and Boland CR: Epigenetics of colorectal cancer. Gastroenterology 143: 1442-1460, e1, 2012.

102. Schneider-Stock R, Kuester D, Ullrich O, Mittag F, Habold C, Boltze C, Peters B, Krueger S, Hintze C, Meyer F, et al: Close localization of DAP-kinase positive tumour-associated macrophages and apoptotic colorectal cancer cells. J Pathol 209: 95-105, 2006.

103. Mukhopadhyay R, Ray PS, Arif A, Brady AK, Kinter M and Fox PL: DAPK-ZIPK-L13a axis constitutes a negative-feedback module regulating inflammatory gene expression. Mol Cell 32: 371-382, 2008

104. Kamal M, Pawlak A, BenMohamed F, Valanciuté A, Dahan K, Candelier M, Lang P, Guellaën G and Sahali D: C-mip interacts with the p85 subunit of PI3 kinase and exerts a dual effect on ERK signaling via the recruitment of Dip1 and DAP kinase. FEBS Lett 584: 500-506, 2010. 